\title{
El abordaje del pathos humano en Marx, Freud y Nietzsche
}

\section{The approach of human pathos in Marx, Freud and Nietzsche}

\author{
MARIELA CECILIA GENOVESI \\ Universidad de Buenos Aires - CONICET
}

Recibido: 09/05/2017 Aceptado:13/06/2017

\section{RESUMEN}

El siguiente trabajo tiene como objetivo desarrollar la forma a través de la cual Marx, Freud y Nietzsche han pensado las causas del pathos humano — entendido éste en su doble valencia de sufrimiento y pasión - a partir de un abordaje materialista de las nociones de sensibilidad y afectividad. En consecuencia, se hará énfasis en el concepto de "sensibilidad práctica», adoptado por el joven Marx de los Manuscritos económicos filosóficos de 1844, y en el de «voluntad de poder», presente en el esbozo de «la teoría de los afectos» en los Fragmentos póstumos del último Nietzsche. Un encuentro que, pese a las distancias biográficas, teóricas e históricas, es posible trazar a partir del concepto de sensibilidad y que incluye a Freud como intermediario, ya que desde su perspectiva psicoanalítica, él también se ocupó de comprender la naturaleza indomable de nuestra constitución psíquica.

\section{PALABRAS CLAVE}

SENSIBILIDAD PRÁCTICA, AFECTIVIDAD, VOLUNTAD DE PODER, AFECTOS

\section{ABSTRACT}

The following work aims to develop the form through which Marx, Freud and Nietzsche have thought the causes of human pathos - understood it in its double meaning of suffering and passion - from a materialistic approach to the notions of sensitivity and affectivity. Consequently, 
emphasis will be placed on the concept of «practical sensibility», adopted by the young Marx of the Economic and Philosophical Manuscripts of 1844, and on the «will to power» present in the rough draft of «the theory of affections» in the Posthumous Fragments of the last Nietzsche. An encounter that, despite the biographical, theoretical and historical distances, it is possible to draw from the concept of sensitivity and that includes Freud as an intermediary, because from his psychoanalytic perspective he was also concerned in understanding the indomitable nature of our psychic constitution.

KEYWORDS

PRACTICAL SENSITIVITY, AFFECTIVITY, WILL TO POWER, AFFECTS

\section{INTRODUCCIÓN}

EN JULIO DE 1964 ACONTECE el VII coloquio filosófico internacional en Royaumont, Paris, dedicado a Nietzsche. En dicha oportunidad, Foucault, presenta su ponencia «Nietzsche, Freud y Marx», en la cual intenta postular de qué manera estos tres autores han hecho emerger en el siglo XIX un nuevo tipo de hermenéutica basada en otras técnicas interpretativas que modifica la manera en la que los signos podían ser interpretados. Al respecto, una de las tesis principales de Foucault radica en sostener que a partir de Freud, Marx y Nietzsche, «los signos se han sobrepuesto en un espacio mucho más diferenciado, según una dimensión que se podría llamar de profundidad, pero a condición de no entender por ella la interioridad, sino, al contrario, la exterioridad». ${ }^{1}$ Es decir, se trata de la puesta en juego de una estrategia interpretativa en la que el intérprete, con el afán de descender y ser un «buen escudriñador de los bajos fondos» ${ }^{2}$ pueda descubrir que la profundidad, entendida como interioridad, es «un ademán y un pliegue de la superficie». ${ }^{3}$ En consecuencia, intenta situar a cada uno de estos tres autores en un «espacio de interpretación» propio: Nietzsche se situaría en la crítica hacia esa noción de profundidad, Marx en el análisis de la superficialidad burguesa (que trastoca con su «exterioridad» las formas de la «interioridad» humana) y Freud en el desciframiento de la materialidad de los síntomas (signos) que se presentan en la superficie del cuerpo.

Por consiguiente, y en lo que respecta a los objetivos de este trabajo, se intentará retomar ese posicionamiento que Foucault le asigna a Freud, a Marx y a Nietzsche pero para analizar el tratamiento, o más precisamente, la «técnica interpretativa» que los tres han desarrollado para pensar las causas del pathos humano - entendido éste en su doble valencia de sufrimiento y pasión - al ubicarlo en el estudio material de la sensibilidad y la afectividad.

1 M. Foucault, Nietzsche, Freud, Marx. Barcelona: Anagrama, 1981, p. 29.

2 Foucault citando a Nietzsche [Cf. Aurore, § 446.], Ibid., p. 29.

3 Ibid., p. 29. 
En El malestar de la cultura Freud se pregunta por qué al hombre le resulta tan difícil ser feliz. Y su respuesta radica en el señalamiento de las tres fuentes del sufrimiento humano: «la supremacía de la Naturaleza, la caducidad de nuestro cuerpo propio y la insuficiencia de nuestros métodos para regular las relaciones humanas en la familia, el Estado y la sociedad» ${ }^{4}$. De estos tres motivos, nos interesa centrarnos en el tercero: el de origen social. Motivo hacia el cual Freud también dirige su mirada, al sospechar que «ahí podría ocultarse una porción de la indomable naturaleza de nuestra propia constitución psíquica». ${ }^{5}$

Hacia la formación y constitución de «esa naturaleza» se dirigirá la mirada de este trabajo al hacer énfasis en el concepto de «sensibilidad práctica», adoptado por el joven Marx de los Manuscritos económicos filosóficos de 1844, y en el de «voluntad de poder», presente en el esbozo de «la teoría de los afectos» en los Fragmentos póstumos del último Nietzsche. Un encuentro que, pese a las distancias temporales, geográficas, biográficas, teóricas e históricas, es posible trazar para intentar entender los pliegues y bordes del entrecruzamiento entre lo interior y lo exterior, necesarios para llegar a la profundidad de ese pathos existencial.

En 1844, nos encontramos con un Marx incipiente, aún no abocado al desarrollo de su materialismo histórico ni de su teoría social y económica del capital, que propone pensar al hombre como un ser social a partir de su naturaleza sensible. Esa «naturaleza» que «une» al hombre con lo otro y con los otros y que le permite constituir su «humanidad» y devenir en «ser humano»-su sinnlichen Wesenskräfte, su «fuerza esencial natural»-. Una sensibilidad, entonces, que va a ser concebida como «práctica», como «material» y que, por lo tanto, se va a encontrar «condicionada» por su tiempo y espacio social.

Nietzsche, por su parte, ya hacia el final de su vida, solo y aislado, ensayando fragmentariamente entre una publicación y otra los principios de su «obra capital», intentará trazar la idea matriz de ésta haciendo eje en la «voluntad de poder» y en la «transvaloración de todos los valores» para el surgimiento y la formación de otro tipo de humanidad. Siendo «consciente» de todo lo malo y egoísta del ser humano y de sus «instancias» de apego (la producción de conocimiento, de arte, de vida y sus deseos de reconocimiento), «hace estallar» los esencialismos, los determinismos y hasta el propio racionalismo, al postular su tesis interpretativa y perspectivista del conocimiento, y al pensar

4 S. Freud, «El malestar en la cultura» en Obras Completas, Tomo III, tr. Luis LópezBallesteros y de Torres. Madrid: Biblioteca Nueva y Siglo XXI, 2012, p. 3031.

5 Ibid., p. 3031. 
en la raíz afectiva, múltiple, contingente y contradictoria de toda actividad representativa — «Unter jedem Gedanken steckt ein Affekt» (Por debajo de cada pensamiento se esconde un afecto» ${ }^{6}$ ).

Por consiguiente, y así como Marx procuró entender a la «sensibilidad» como origen de todo conocimiento y como condición de posibilidad del devenir humano al hacer foco en la «formación» de los «sentidos» humanos; Nietzsche, intentará meditar sobre lo mismo, pero haciendo hincapié en la «afección», en la «lucha de afectos» interna del hombre; «lucha» condicionada por lo «externo» también, pero que remite a los «impulsos» que constantemente se presentan como «fuera de control» y con «vida» «propia».

Dentro de esta lectura, Freud será posicionado como «autor bisagra» entre ambas posturas, debido a que a lo largo de su extensa obra, se dedicará a pensar en el contraste entre Eros y Tánatos, es decir, las pulsiones de vida, amor y unión, en lucha con las pulsiones de muerte, agresión y destrucción, presentes en la constitución psíquica de cada individuo. Constitución que si bien para Freud tiene una raíz filogenética, también presenta un componente social que le es inexpugnable.

\section{LA «SENSIBILIDAD PRÁCTICA» Y LA HUMANIZACIÓN DEL HOMBRE}

Empezaremos entonces por el joven Marx, quien en los Manuscritos económicos filosóficos define a la sensibilidad, como aquella «fuerza esencial natural» — sinnlichen Wesenskräfte — y la relaciona con los «sentidos sensibles» - los cinco sentidos - y los sentidos llamados «espirituales o prácticos»—voluntad, amor, deseo-. Fuerzas esenciales o sentidos que sólo pueden ser humanos mediante el vínculo del hombre con otro, es decir, mediante la materialización del ser social del hombre. Al respecto, lo que Marx intenta postular es que en la «naturaleza humana» subyace una «fuerza esencial» que posee un carácter potencialmente humanista al ponerse el hombre en contacto con otros hombres. Es decir, al vincularse. Esa fuerza

6 Nietzsche, F. Nachgelassene Fragmente 1885-1886, 1 [61], KSA 12, § 53.

7 «Sinnlich» quiere decir «sensual» cuando se aplica al hombre (mensch) o puede hacer referencia «a los sentidos, lo sensorial» cuando remite a «Eindruck» (impresión). En este caso, corresponde la segunda acepción, por eso «Sinnlichen» se traduce como «sensibilidad». Por su parte, «Wesenskräfte» es la combinación de «wesen»— palabra que se utiliza para hacer referencia a «la naturaleza humana», pues significa tanto «criatura, ser» cuando remite a «Geschöpf», como «esencia», cuando hace hincapié en el carácter natural (Natur / Charakter) - y «kräfte» que significa fuerza, vigor, poder, potencia. Más adelante, se verá como utiliza Nietzsche estas nociones. 
esencial, no sería otra que la «sensibilidad», que es la que le permite al hombre, justamente, convertirse en un ser social al dejarse «afectar», «formar» por aquello exógeno que lo «humaniza»:

La esencia humana de la naturaleza no existe más que para el hombre social, pues sólo así existe para él como vínculo con el hombre, como existencia suya para el otro y existencia del otro para él, como elemento vital de la realidad humana; sólo así existe como fundamento de su propia existencia humana. ${ }^{8}$

Lo que Marx está advirtiendo a lo largo de esta frase, es que en esa condición natural y sensible descansa la condición de posibilidad del ser social y humano del hombre. Por eso Marx lo concibe como «elemento vital de la realidad humana», como fuerza impulsora de esa realidad, como «fundamento», entonces, «de la existencia humana». ${ }^{9}$ Pero Marx también piensa en la historia del «proceso de humanización» de esa fuerza esencial natural, es decir, en la «forma efectiva» mediante la cual el hombre se humaniza, se subjetiviza. Forma, que respondería a los principios de la propiedad privada presente en la «forma social capitalista».

¿Cómo es que se produce este proceso? El sentido de las fuerzas naturales esenciales se humaniza al ponerse en contacto con un objeto al cual cada fuerza esencial le va a asignar una forma peculiar según sus propias potencialidades (el oído, oirá; el olfato, olerá, etc) al tiempo que se objetivizará dando cuenta de la peculiaridad subjetiva del hombre: qué oirá y cómo lo oirá, por ejemplo, responde a rasgos de su singularidad. En consecuencia, dicha peculiaridad subjetiva surge como correlato del entramado social en el que fue «subjetivizado».

Por eso, para Marx, esos «sentidos», esas «fuerzas esenciales», deben ser «creadas». Aquí es donde interesa apreciar entonces que esa creación, responde a condiciones socio-políticas porque tanto el «órgano inmediato» (el oído, por ejemplo) como su producto (la pieza que escucha u oye) se convierten en un «órgano»y en una «manifestación» social, al estar atravesados por y configurados en la «forma de humanización» dada a partir de los principios de la propiedad privada. Principios estos que, mediante tal proceso de subjetivación, pueden para Marx «perfeccionar su dominio sobre el hombre, y convertirse, en su forma más general, en un poder histórico-universal». ${ }^{10}$ Siendo ésta la forma a través de la cual se lo humaniza al hombre, se lo convierte en un ser social, al «humanizar» las fuerzas esenciales con las que

8 K. Marx, Manuscritos económicos filosóficos. Buenos Aires: Ed. De la Campana, 2011, p. 115.

9 Ibid., p. 116.

10 Ibid., p. 109. 
se vincula a otros y con sí mismo. Esta resulta ser, entonces, la «creación del sentido humano» de acuerdo con determinados principios de vinculación y de acceso «sensible» a lo otro:

La propiedad privada nos ha hecho tan estúpidos y unilaterales que un objeto sólo es nuestro cuando lo tenemos, cuando existe para nosotros como capital o cuando es inmediatamente poseído, comido, bebido, vestido, habitado, en resumen, utilizado por nosotros. Aunque la propiedad privada concibe, a su vez, todas esas realizaciones inmediatas de la posesión sólo como medios de vida y la vida a la que sirven como medios, es la vida de la propiedad, el trabajo y la capitalización. ${ }^{11}$

La vida de la propiedad se resumirá entonces para Marx, en sentir, desear, pensar, hacer, ver, escuchar...para tener, para poseer, para llegar a un fin útil; cuando en realidad estas potencialidades y aptitudes podrían responder a principios y a lazos comunitarios de reciprocidad y desinterés entre los hombres y entre éstos y los objetos. Al respecto, concluye Marx: «ha aparecido así la simple enajenación de todos estos sentidos, el sentido del tener»». ${ }^{12}$ Sentido que da cuenta de la producción y efectivización social de la vida humana enajenada porque el hombre no sólo vive de manera alienada la potencialidad de sus fuerzas esenciales y los sentidos asociados a estas, sino que tampoco reconoce a los objetos humanos como creados por él.

En consecuencia, existiría para Marx la posibilidad de que la «humanización» de las fuerzas esenciales fuera distinta si la lógica de «formación» de esa «humanización» también lo fuera. Algo con lo cual Freud, no estaría del todo de acuerdo, puesto que para él, el hombre «convive» con un antagonismo instintivo, con el contraste entre Eros y Tánatos, es decir, las pulsiones de vida, amor y unión, en lucha con las pulsiones de muerte, agresión y destrucción. Dialéctica presente en la constitución psíquica de cada individuo, dialéctica que el propio Nietzsche percibe, pero para quien, no obstante, también sería susceptible de «domesticar» a partir de otro marco de subjetivación diferente al constituido por lo que él denomina la «voluntad de dominio» presente en los «valores de la decádence» que predica la moral cristiana. Por eso, a continuación, hablaremos de Nietzsche y del concepto de «voluntad de poder».

\section{DE LA «SENSIBILIDAD PRÁCTICA» A LA «VOLUNTAD DE PODER»}

El concepto de «voluntad de poder» resulta ser un concepto complejo porque se corresponde con el deseo de querer llevar a cabo un proyecto 
de carácter último e integrador de su obra que Nietzsche denominará: «La voluntad de poder. Ensayo de una transvaloración de todos los valores». El afán de querer desarrollar tal iniciativa se expresa en varios parágrafos del tomo IV de los Fragmentos Póstumos ${ }^{13}$ —obra póstuma que resulta ser el compendio de una serie de reflexiones, esbozos y anotaciones de carácter discontinuo y fragmentario que datan de 1870 a 1889 , correspondiendo el tomo IV al período final de la obra de Nietzsche (1885-1889), dentro de la cual desarrolla su genealogía de la moral, la teoría perspectivista del conocimiento y el deseo de querer llevar a cabo una filosofía nihilista del futuro-. En consecuencia, éste contendrá ideas que aparecen en: Asi habló Zaratustra. (1883-1885), Más allá del bien y del mal (1886), La genealogía de la moral (1887), Ecce homo (1889), entre otros. Pese a su carácter disgregado, este tomo de los Fragmentos Póstumos adquiere relevancia por la serie de premisas expresadas allí que atienden a diversos problemas epistemológicos y que apuntan, justamente, a la producción de una obra de carácter global que ha quedado inconclusa. ${ }^{14}$ Dicha obra tenía por objetivo desarrollar el concepto de voluntad de poder y vincularlo a una teoría de los afectos, debido al énfasis presente en varios de los parágrafos escritos por Nietzsche de hallar la génesis afectiva y pulsional del pensamiento. Ese sería su gran aporte a la teoría del conocimiento, y en consecuencia, a todo lo «conocido», a todo «valor», a todo «concepto» de lo «humano». En lo que resta de este artículo, se intentará por lo tanto, desarrollar algo de esto en relación a lo dicho hasta el momento con referencia a Marx. Pasemos entonces a Nietzsche y a como él piensa a los afectos y a la sensibilidad, es decir, al pathos humano.

¿Pero que es la vida? Aquí es necesaria, por lo tanto, una versión más precisa del concepto de 'vida': mi fórmula para ello reza: la vida es voluntad de poder. ${ }^{15}$ El hombre como una multiplicidad de 'voluntades de poder': cada una con una multiplicidad de medios expresivos y formas. Las presuntas 'pasiones singulares' son sólo unidades ficticias, en la medida en que aquello que, proveniente de los diferentes impulsos básicos, entra en la conciencia como algo homogéneo. ${ }^{16}$

13 Siguiendo a Mónica Cragnolini, las obras de F. Nietzsche se citan como KSA a partir de las Sämtliche Werke. Kritische Studienausgabe in 15 Bänden, Hrsg. von G. Colli und M.Montinari, Berlin-New York, Walter de Gruyter, 1980). Los fragmentos póstumos 1885-1887 IV o Nachgelassene Fragmente 1885-1887 (en adelante NF) corresponden al Tomo 12 de la KSA — según lo advierte Joan Llinares en su nota introductoria-.

14 Ver la introducción escrita por Joan B. Llinares en la edición de Tecnos dirigida por Diego Sánchez Meca y las opiniones de W. Stegmaier y S. Rabade, estudiosos de la obra de Nietzsche citados en la tesis doctoral de Raúl E. de Pablos Escalante "La filosofía vivida: pensamiento y transformación en Spinoza y Nietzsche".

15 NF 1885-1887, 2 [190], KSA 12, § 132.

16 NF 1885-1886, 1 [58], KSA 12, §52. 
La vida como «voluntad de poder» in-exhausta y fecunda, que hunde sus «raíces» en una serie de «impulsos básicos» que «se sienten, en referencia a cada uno de los otros, inhibido o favorecido, o adulado», ${ }^{17}$ es decir, en pugna, en lucha, porque «cada uno tiene su propia ley evolutiva (sus subidas y bajadas, su tempo, etc)». ${ }^{18}$ Estos impulsos básicos, no serían otros más que los afectos, a los cuales Nietzsche también concibe como una «fuerza natural». Es decir, éstos no sólo constituirían una fuerza impulsora, sino una fuerza natural en un sentido análogo a la sensibilidad práctica de Marx. ${ }^{19}$ Porque si bien estos

17 NF 1885-1886, 1 [58], KSA 12, § 52.

18 NF 1885-1886, 1 [58], KSA 12, § 52.

19 Al respecto, cabe realizar una observación. Marx no usa el término «afecto» o «afección», por el contrario, él utiliza la noción de «sensibilidad»— — tal como se explicó más arriba - haciendo referencia a la «formación de los sentidos humanos»; es decir, Marx está intentando pensar en la conformación y el condicionamiento de «esas fuerzas esenciales humanas» que vinculan al hombre con lo «exterior», con lo que «viene de afuera». Por el contrario, Nietzsche, está pensando en la «naturaleza arrebatada» del hombre, en sus «impulsos pasionales» en aquello que «le viene de adentro», como lo más «propio» de sí — propio, no el sentido de propiedad o pertenencia, sino de «condición», de «rasgo distintivo»—. Por eso, Nietzsche sí utiliza el término de Affekt (afecto) y Affekte (afectos), término que en alemán se encuentra vinculado a lo pasional (Leidenschaft), a lo emocional (Gemütsbewegung) y a los impulsos (Geschlechtlich). Por eso también, suele utilizar el término «trieb» — instinto (Instinkthaft), impulso (Geschlechtlich), inclinación (Neigung) o brote (an Baum) —en lugar de «Kraft»» (fuerza) tal como lo emplea Marx. Otros términos vinculados a la afección pueden ser: Zuneigung — pero remite al afecto en términos de cariño, simpatía, amor-, Leiden — que hace referencia a la afección en términos de dolencia, como «pathos», padecer- - Gefühle que hace referencia a la afectividad como sentimiento (Seelisch) o sensación (Physisch). No obstante, cuando hace mención a los «sentidos» — de manera análoga a Marx—- sí utiliza los términos de «Sinnlich», «Sinn» y «Kraft», incluso habla de «Wesen» como esencia (cuando en otros parágrafos, para remitir a la esencia — al pelearse con los esencialistas — lo hace utilizando el término «Essenz»): «Die geistigsten Menschen empfinden den Reiz und Zauber der sinnlichen Dinge wie es sich die anderen Menschen, solche mit den 'fleischernen Herzen' gar nicht vorstellen können - auch nicht vorstellen dürften:- - sie sind Sensualisten im besten Glauben, weil sie den Sinnen einen grundsätzlicheren Werth zugestehen als jenem feinen Siebe, dem VerdünnungsVerkleinerungsapparate, oder wie das heißen mag, was man, in der Sprache des Volkes, 'Geist' nennt. Die Kraft und Macht der Sinne — dies ist das Wesentlichste an einem wohlgerathenen und ganzen Menschen: das prachtvolle 'Thier' muß zuerst gegeben sein-was liegt sonst an aller 'Vermenschlichung'!» (En Nietzsche, F. Nachgelassene Fragmente (1885-1889) [Versión original de los fragmentos en versión electrónica The Nietzsche Channel] Disponible en: http://www. thenietzschechannel.com/notebooks/german/nache/nache1c.htm). [Traducción: «Los hombres más espirituales sienten el atractivo y el encanto de las cosas sensibles de un modo que los demás hombres, los de 'corazones carnales' no pueden — ni tampoco deben — imaginar: son sensualistas con la mejor buena fe, porque conceden a los sentidos un valor más fundamental que a ese fino 
afectos son concebidos como «inconscientes», como «impulsos básicos» y como «apetitos primitivos», también — y en cuanto a su «puesta en forma»van a estar vinculados a los «sentidos orgánicos» naturales y fundamentales del hombre para construirse a sí mismo y vincularse a los demás. En palabras de Nietzsche:

Útiles son todos los afectos, unos directa, otros indirectamente; respecto de la utilidad es absolutamente imposible establecer una serie de valores, - tan cierto como que, medido económicamente, las fuerzas de la naturaleza son todas buenas, por mucha fatalidad terrible e irrevocable que salga de ellas. A lo sumo podría decirse que los afectos más potentes son los más valiosos: en la medida en que no hay mayor fuente de fuerza. ${ }^{20}$

Los movimientos son síntomas, los pensamientos también son síntomas: detrás de ellos se nos muestran los apetitos, y el apetito fundamental es la voluntad de poder. ${ }^{21}$

¿Qué hace que algunos «afectos» crezcan, suban o bajen, o se inhiban? Aquello que los «forma» o los «alimenta»; y aquí entra la cuestión «bivalente» de la «voluntad» que podría ser caracterizada como «de dominio». Por un lado, el hombre «quiere más», eso Nietzsche lo considera algo constitutivo de la especie humana, que no busca saciar necesidades, autoconservarse, sino «ser más», crecer; por eso, el impulso más básico de la voluntad de poder sería el «querer más». Pero, por el otro, ese impulso de «querer más», se complementa o se enfatiza con el surgimiento de la «estimación» o «valoración perspectivista» que le otorga asidero, forma y hasta cierta «homogeneidad» a los actos, a los sentimientos y al pensar. Puesto que, tal como postula Nietzsche, la naturaleza nos proporcionó de una fuerza potente, activa y afectiva, que en sí no es ni buena ni mala, es una potencia presente en el hombre, cuya «red», «área»o «forma» «humana» de materialización efectiva dependerá del «marco», del «entorno» social que la moldee:

La vida no es adaptación de condiciones internas a condiciones externas sino voluntad de poder que, desde el interior, somete e incorpora a sí cada vez más «exterior». ${ }^{22}$

filtro, ese aparato de dilución, de reducción o como quiera que se llame eso que en el lenguaje del pueblo se denomina 'espíritu'. La fuerza y el poder de los sentidos — es lo más esencial de un hombre logrado y total: primero tiene que estar dado el 'animal' magnifico — iqué importa si no toda la 'humanización'!» (NF 1886-1887, 5 [34], KSA 12, § 155)].

$20 \mathrm{NF} 1887,10$ [133], KSA 12, § 340/41 (la cursiva es nuestra).

21 NF 1885-1886, 1 [59], KSA 12, § 53.

22 NF 1886-1887, 7 [9], KSA 12, § 211. 
La medida del querer-conocer depende de la medida del crecimiento de la voluntad de poder de la especie: una especie capta tanta realidad como capacidades tiene para dominarla, para ponerla a su servicio. ${ }^{23}$

Los «afectos», la «voluntad de poder» constitutiva del hombre, resulta estar entonces, condicionada por las «estimaciones de valor» propias de los cuatro grupos de «dominio» $\mathrm{y}$ «formalización» de los sentimientos, hábitos y pensamientos «dominantes»: la moral, el estado (o los regímenes políticos), la economía y la ciencia. Esto significa que el «carácter interpretativo de todo acontecer» ${ }^{24}$ que circunda al hombre, tendrá que ver con las «formas» a través de las cuales «su perspectiva» volitiva, sensitiva y cognitiva, esté «afectada» por los afectos inherentes a su voluntad de poder, estando éstos - $\mathrm{y}$ en consecuencia su perspectiva volitiva, sensitiva, etc - "condicionada» por la «perspectiva macro» de la voluntad de dominio de su tiempo y espacio histórico-social. Por eso Nietzsche afirma: «la moral es una parte de la doctrina de los afectos: ¿hasta dónde penetran los afectos en el corazón de la existencia?»». ${ }^{25}$ Es decir, y sumergiéndonos primero en la «perspectiva de la moral cristiana», ¿Qué afectos son buenos? ¿Cuáles son malos? ¿Cómo controlarlos? ¿Cuál debe imponerse sobre otro? Controles, «interpretaciones» que se darían en el terreno consciente, pero que, no obstante, operan a nivel inconsciente. Por eso Nietzsche, piensa en una «división del trabajo de los afectos» como correlato de los «condicionamientos» morales:

¿Qué debo hacer? y ¿qué móviles deben impulsar mi acción? Preguntas que sólo pueden ser respondidas de una forma laboriosa y difícil. Si la razón humana se ha desarrollado con tanta lentitud que hasta cabe negar su crecimiento a lo largo de la historia, ia qué hay que imputar este fenómeno sino a esta solemne presencia (a esta omnipresencia, diría yo) de los mandamientos morales, que ni siquiera permite al individuo que se plantee el por qué y el cómo de sus actos? ¿No trata la educación de suscitar en nosotros sentimientos patéticos, de hacernos huir a las tinieblas cuando nuestra naturaleza necesitaría conservar toda su claridad y su sangre fría, por así decirlo, en todas las circunstancias elevadas e importantes? ${ }^{26}$

23 NF 1888, 14 [122], KSA 12, § 561.

24 NF 1885-1886, 1 [115], KSA 12, § 60.

25 NF 1885-1886, 1 [73], KSA 12, 55.

26 M (Aurora), KSA 3. Versión española (1994), Madrid, M. E. Editores, S. L. Aforismo $107, \S 51$. 
Una división del trabajo de los afectos en el interior de la sociedad: de manera tal que los individuos y los estamentos cultiven una especie de alma incompleta, pero precisamente por ello más útil. En qué medida en cada tipo dentro de la sociedad algunos afectos se han vuelto casi rudimentarios (en beneficio del desarrollo más fuerte de otro afecto). ${ }^{27}$

Pero, la forma mediante la cual esa voluntad de poder incorpora «a si» eso exterior, tendrá que ver con la voluntad de dominio «propia», pero también con la voluntad de dominio «externa» que «condiciona» a la propia. Por eso, «nos estará permitido» ver, oír, pensar, desear, querer «ciertas» formas en lugar de otras, así como también «se incentivará» la «utilidad» de ciertos afectos por sobre otros, o una forma de ser o sentir por sobre otra. Puesto que, de lo que se trata $-\mathrm{y}$ por eso Nietzsche lo piensa como una tríada, como una conjunción de sentimientos/acciones/pensamientos_ es de «formar» al hombre en su sensibilidad, su moralidad, su accionar, su pensamiento...en fin, en su vida diaria, constante y rutinaria. ${ }^{28} \mathrm{O}$, dicho en otras palabras, en su «voluntad de poder», como modo y medio de la potencia de su existencia. En ese sentido, la «voluntad de dominio» puede ser interpretada como el «existente» de esa «voluntad de poder», es decir, como la forma actualizada, inculcada y desarrollada en el hombre para «ser», para vivir de una determinada manera de acuerdo con «las estimaciones de valor» de esos cuatro grupos que lo rodean.

La tarea consiste en hacer al hombre lo más utilizable posible, y en acercarlo, en la medida en que se pueda, a la máquina infalible: para este fin hay que equiparlo con virtudes de máquina (tiene que aprender a sentir que los estados en los que trabaja de modo utilizable y maquinal son los más valiosos: para ello es necesario hacer que los otros le disgusten lo más posible, le resulten lo más posible peligrosos y desacreditados). ${ }^{29}$

Y aquí llegamos al mayor acercamiento «semántico» a Marx. Si bien Nietzsche no habla de la «lógica de la propiedad privada» ni del «mundo capitalista», sí dirá que las «estimaciones de valor» que hacen posible el surgimiento de ciertas «interpretaciones» o «formas concretas» de la

27 NF 1887, 10 [8], KSA 12, § 299.

28 En palabras de Nietzsche: «Si agudizáramos o embotáramos diez veces nuestros sentidos, sucumbiríamos. El tipo de sentido está en relación con algo que sirve de intermediario para la posibilidad de conservación. Igualmente respecto de lo que sentimos como grande, pequeño, cercano, lejano. Nuestras 'formas' — no hay nada allí que pudieran percibir otros seres diferentes del hombre: —nuestras condiciones de existencia prescriben las leyes generales dentro de las cuales vemos, nos está permitido ver, formas, figuras, leyes» en NF 1886-1887, 6 [8], KSA 12, § 180 (el subrayado es nuestro).

29 NF 1887, 10 [11], KSA 12, § 300. 
«voluntad de poder» del hombre están «condicionadas por la clase, por la raza y los valores dominicales y cotidianos».$^{30}$ De ahí también el empleo de la metáfora de la «máquina»: a la «tarea» de «hacer al hombre» «lo más utilizable posible» para acercarlo a «la máquina infalible». Estimaciones de valor que, por otra parte, constituyen «creaciones» humanas, al no ser ni «cosas en sí» ni «divinidades», y por eso mismo, susceptibles de ser alteradas y transformadas. Sin embargo, y así como para Marx el hombre vivía en forma alienada la potencialidad de sus fuerzas esenciales y las producciones humanas sensibles y cognitivas asociadas a éstas, para Nietzsche, el hombre se ha olvidado de que él ha creado esas «estimaciones de valor» que lo «configuran»y «afectan». En palabras de Nietzsche:

Demostrar la necesidad de que a un consumo cada vez más económico del hombre y de la humanidad, a una 'maquinaria' de intereses y realizaciones cada vez más firmemente imbricados entre si le corresponde un contramovimiento. Lo caracterizo como la secreción de un excedente de lujo de la humanidad: en ella debe salir a la luz una especie más fuerte, un tipo superior, que tiene condiciones de surgimiento y de conservación diferentes que el hombre medio. Mi concepto, mi símil para este tipo es, como se sabe, el término de 'superhombre'. ${ }^{31}$

Nuestro 'nuevo mundo': tenemos que conocer hasta qué punto somos los creadores de nuestros sentimientos de valor, $-\mathrm{y}$ por lo tanto podemos poner 'sentido' en la historia. ${ }^{32}$

De esta manera, sólo el «ultrahombre» como especie «más fuerte» podría «desmundanizar» al mundo de los «valores de la decádence» que forman al hombre como un viviente mediocre, como una máquina y un ser subyugado por dominios egoístas apuntalados en valores igualmente egoístas — porque el «amor al prójimo» prodigado por la «compasiva» moral cristiana esconde tras de sí la consolidación de una «perspectiva interesada»: «actúo, no para salvar al prójimo, sino para salvarme yo». Así, y frente al sujeto que domina, que se cree dueño de la realidad, la «voluntad de poder» del ultrahombre supondría el abandono de querer imponer la propia voluntad a lo que acontece. Se trataría ésta de una aceptación de la vida en todos sus aspectos, aceptación desinteresada sostenida por valores igualmente desinteresados. Valores, diría Marx, que apuntarían a la emancipación plena de todos los sentidos y cualidades humanas; a la superación de la matriz de producción y formación de «humanidad» basada en la lógica de la propiedad privada. 
Ese «abandono» del ultrahombre supondría asimismo, una aceptación de los azares y contingencias de la vida en lugar de su «conservación»; situación que nos sitúa en otro aspecto de la problemática. La idea de «conservación» está vinculada al «querer más» y a la propiedad, pero también, se encuentra asociada al apego del hombre a su raciocinio, es decir, a los productos de la razón.

\section{DE LA «RAZÓN» AL «ELLO»Y A LAS HUELLAS INCONSCIENTES DEL CUERPO}

Tal como lo postuláramos más arriba, aquello que el «hombre conozca» surge de una «interpretación», puesto que no hay «ningún acontecimiento en sí», ninguna «cosa en sí» que detente un sentido «determinado» o «propio». Ahora bien, el problema estriba en el «¿Quién?»: ¿Quién interpreta? Y Nietzsche es enfático en eso al afirmar que no hay un «quién último», no hay un «sujeto», una «razón» que interprete — tal como los filósofos de la Modernidad desde Descartes hasta Kant así lo habían creído- sino que la acción, el efecto de «interpretar» «en cuanto una forma de voluntad de poder», «tiene existencia» «como un proceso, un devenir»... es decir, «como un pathos», «como un afecto». ${ }^{33}$ Afectos que son corporales, sensaciones que aparecen y desaparecen en el cuerpo, que acontecen en el vivir, que impulsan las acciones y pensamientos del «sujeto». Por eso Nietzsche también afirma que «detrás de todo pensamiento, se esconde un afecto». El pensar mismo, desde su perspectiva, no es una «unidad» «cerrada», «transparente», sino todo lo contrario, «es un signo», un «síntoma» de una «lucha de afectos»; lucha que se «esconde», que está por detrás, que no aflora a la superficie de la «conciencia», que envuelve una «multiplicidad de voluntades de poder», de «unidades ficticias» que provienen de impulsos básicos. Por consiguiente, no puede suponerse la existencia de un «yo» «propietario» de esas interpretaciones que fluyen a la conciencia. En consecuencia, Nietzsche trastoca el modelo representativo cartesiano — «yo pienso»— y postula la idea del «ello piensa», siendo el «ello» no un sujeto, sino, el devenir propio de ese acontecer afectivo que se podría situar en el cuerpo.

Esto nos conecta directamente con Freud, quien identifica en tres figuraciones, los tres tipos de instancias a partir de las cuales ese «ello inconsciente» se manifiesta y emerge en tanto pathos en el cuerpo. Figuraciones, por otra parte, que permiten caracterizar al ser humano como «ser viviente»y comprender al sujeto en términos de «naturaleza» y «cultura»; es decir, como ser natural, biológico y como ser simbólico, cultural e histórico. Puesto que los tres tipos de «figuraciones» que esboza Freud permiten pensar la articulación física (biológica) y psíquica (simbólica) a través del cuerpo: el cuerpo sostén,

33 NF 1885-1887, 2 [151], KSA 12, § 123. 
el cuerpo apoyatura y el cuerpo apremio de la vida. Figuraciones, asimismo que nos colocan ante otra disyuntiva: el hombre tampoco es «dueño» de su cuerpo, el hombre es con él y a través de él: de él y de sus afectos, aquellos que «pulsan» — desde la perspectiva de Freud - por la conservación del placer o del displacer impulsados por las fuerzas naturales que lo habitan.

Empezando por el cuerpo sostén, éste podría pensarse como un derivado de la idea griega de «sustrato», de «sustancia», de «causalidad» que permite construir/producir el siguiente pasaje: del cuerpo como sustrato del alma (anima) al cerebro como sustrato del pensamiento. Por lo tanto, ésta sería la primera imbricación entre la diferencia biológica y la cultural, el primer encuentro entre estos dos tipos de «lenguajes» distintos, la base para que tanto la vida psíquica como la vida física construyan subjetividad. Por eso se lo piensa en términos de «sostén» porque el cerebro no es sólo la causa del pensamiento, sino el «sujeto» que sostiene esa diferencia. La diferencia se soporta, porque no hay homologación, un isomorfismo total y pleno, por lo tanto, no puede haber una amalgama, una combinación yuxtapuesta, como así tampoco una «inscripción». Hay soportabilidad y como producto de esa «convivencia», surge un entramado del «entre», uno se apoya en otro: lo psíquico, se apoya en lo físico, y viceversa, porque lo físico, lo biológico, es la base en tanto condición/limitación de todo lo «contingente» que lo simbólico pueda «entrecruzar» con él. Pero, y aquí es donde aparece ese «ida y vuelta» propio del «entre», las limitaciones y condiciones propias de dicha base «biológica/neuronal» también se encontrarán atravesadas por condicionamientos y limitaciones socio-culturales. No obstante, sobre la base de esta apoyatura también es posible hallar la premisa freudiana de la «roca viva», del «lecho de roca»; es decir, de las «diferencias existentes en el cuerpo, no penetrables, no atravesables, no modificables por la historia, por la cultura, por la biografía». ${ }^{34}$ En estos términos también, hay que pensar a ese pathos, a esa fuerza afectiva, a ese quantum que «mueve» al hombre, que lo «hace ser» como especie «sensible y social».

Y aquí aparece, la otra figura, la que sí puede ser articulable entre ambas «diferencias» y «maleable» por la cultura: el cuerpo como apuntalamiento, como apoyatura que permite la entrada del Otro. El cuerpo como superficie, ahora sí, de inscripción. Como locus de encarnación del otro en mí; del lugar, el tiempo y la oportunidad del Otro de contacto. Esos momentos, esas zonas, esos encuentros a través de los cuales el Otro puede dejar su huella en nuestro cuerpo, en nuestra sensibilidad inicial al afectarla. Lugar que «se marca» de

34 J. Canteros, «El cuerpo en Psicoanálisis», en Revista de Psicoanálisis. Buenos Aires, Asociación Psicoanalítica Argentina, T. LXIV, No 2, 2007, p. 282. 
emociones y de cargas pulsionales. Lugar, que remitirá a la tercera figura también, la del cuerpo «carne», el cuerpo «como anclaje del sujeto al apremio de la vida». ${ }^{35}$

Esto significa un tipo de anclaje especial del sujeto para con la vida. Por un lado, el «cuerpo orgánico» atado a sus tiempos y necesidades biológicas, y por el otro, el «cuerpo ananké», el cuerpo de la necesidad de satisfacción y protección por el otro semejante (porque el sujeto no puede valerse por sí mismo y se encuentra en un estado inicial de indefensión y desamparo) que tiene que «adaptarse» y pasar del «principio de placer» al «principio de realidad». Así debe enfrentarse a «las fuerzas de la naturaleza que están más allá de los hombres», ${ }^{36}$ a la potencialidad de «la hoja en blanco» de la vida, a sus riesgos y a su misterio sabiendo que en «su cuerpo figura una condición límite» y que no puede escapar «de lo dado, de lo contingente y de la muerte» ya que estas tres instancias están más allá de su deseo. Por lo tanto, estas restricciones del cuerpo suponen una condición para el sujeto, lo marcan, puesto que éste es el cuerpo «sede de la necesidad y fuente de la pulsión», aquel que empuja al sujeto hacia el objeto y lo hace enfrentarse al límite de lo «ideal» y de lo «real» y a hacerse cargo (o no) de las frustraciones que ese empuje conlleva. El sujeto como «capitán de tormenta» de este cuerpo «carne» anclado en el apremio de la vida a partir de las formas puntuales que adquiera tras su encuentro con el Otro (simbólico). El sujeto, entonces, como «capitán de tormenta» de ese pathos, de esa fuerza afectiva pensada por Freud como fuerza pulsional.

Así nos encontramos con otra visión del ultra-hombre, de aquel hombre desprovisto y desapropiado de ese último terreno de sí y de pertenencia plena: su «propio» pensar, su «propia» actividad representativa por sobre su cuerpo y sus afectos. El «ultra-hombre» de Freud, es un capitán de tormenta del pathos que sacude ese cuerpo, ese pensar y ese actuar. Este ultra-hombre, es un hombre de la desposesión, sí, pero aún no de la donación. El ultra-hombre de la donación, del desinterés, del dar-se — tal como lo pensara Nietzschees un hombre que no se deja llevar por esa tormenta pulsional, es un hombre que intenta ser consciente de la potencia de sus afectos y de encausarlos hacia una forma de ser y de sentir en comunidad con sí mismo y con el otro. Es un no-dueño, sí, pero es un no-padecer, también. Es un hombre que convive en plenitud consigo mismo y con los demás. No busca el quantum, busca el quale

35 J. Canteros, «El cuerpo, ¿concepto límite del Psicoanálisis?» en Revista Docta. Buenos Aires: 2014, p. 69.

36 J. Canteros, «Del apremio de la vida al Ananké. O la relación del sujeto con el semejante» en: Revista Argentina de Psicoanálisis. Buenos Aires: Asociación Psicoanalítica Argentina, Tomo XLIX Nº 5-6, setiembre-diciembre, 1995, p. 985. 
simple, sencillo y naturalmente genuino. Hacia ese lugar, hacia ese locus del ser debería evolucionar la sensibilidad práctica de la humanidad.

María Cecilia Genovesi es profesora de la Universidad de Buenos Aires (Argentina) y becaria doctoral del CONICET (Argentina).

Líneas de Investigación:

La incidencia de los afectos y las afecciones en la formación de la subjetividad y en la construcción de los esquemas prácticos y cognitivos.

\section{Publicaciones recientes:}

2018: «A cuarenta años del debate Piaget-Chomsky: Derroteros teóricos y perspectivas actuales», Clareira - Revista de Filosofia da Região Amazônica (Roraima, Brasil) http://www.revistaclareira.com.br/index.php/index/index.

2017: «Historia y Representación: un acercamiento metodológico a partir del pensamiento de Castoriadis, Benjamin y Foucault hacia el campo de lo político», Methaodos. Revista de Ciencias Sociales. Disponible en: https://www.methaodos. org/revista-methaodos/index.php/methaodos

Correo electrónico: mariela.genovesi@gmail.com 